\title{
Chemical Modification of Amino Groups in Mucor miehei Aspartyl Proteinase, Porcine Pepsin, and Chymosin. I. Structure and Function
}

\author{
Jeff L. SMith, ${ }^{\dagger}$ Gail E. Billings and Rickey Y. YADA \\ Department of Food Science, University of Guelph, \\ Guelph, Ontario, Canada NIG 2 WI \\ Received January 11, 1991
}

\begin{abstract}
The effects of chemical modification of $\varepsilon$-amino groups (using the water soluble polyanionic copolymer ethylene/maleic anhydride) on the structure and function of various aspartyl proteinases (the proteinase from the fungus Mucor miehei (MMP), and the mammalian proteinases porcine pepsin and chymosin) were examined. Modification of $100 \%$ of the lysyl residues in the proteinases resulted in an increased milk-clotting to proteolytic activity ratio (MC/PA) for pepsin and chymosin, and a lower MC/PA for MMP. Amino-modified MMP was insensitive to the proteinase inhibitor pepstatin, but modified pepsin and chymosin were inactivated. Modification shifted the $\mathrm{pH}$-activity optimum of the mammalian enzymes by $0.5 \mathrm{pH}$ units to a more alkaline $\mathrm{pH}$ and to a more acidic optimum for MMP. Amino modification also decreased the thermostability of the fungal enzyme. Changes in tertiary structure and significant differences in the proportions of the secondary structure fractions $\alpha$-helix and $\beta$-sheet were evident only for modified MMP. Results from this study suggested that MMP was more susceptible to destabilization by charge alteration than aspartyl proteinases of mammalian origin.
\end{abstract}

Proteinases that successfully clot milk for cheese production belong to the class of enzymes known as aspartyl proteinases (EC 3.4.23). These enzymes are characterized by the presence of two catalytically essential aspartic acid residues, optimal activities at $\mathrm{pH}$ 1.5-5.0, and their susceptibility to inhibition by pepstatin and the active-site-directed affinity labels diazoacetyl-norleucine methyl ester and epoxy( $p$-nitrophenoxy)propane. ${ }^{1,2)}$ All enzymes in this class have an asymmetrically clefted active site formed by two lobes. ${ }^{3)}$ Despite sequence and structural homologies for a number of aspartyl proteinases, ${ }^{4,53}$ dissimilarity in physicochemical properties have been observed, e.g., chymosin has a high milk-clotting to proteolytic activity ratio (MC/PA) while porcine pepsin and Mucor miehei proteinase (MMP) have a lower ratio. ${ }^{6,7)}$ In addition, MMP is a glycoprotein with high thermostability. ${ }^{8)}$ Continued prote- olysis following curd cooking is thought to result in the development of bitter flavors and undesirable product softening. ${ }^{9)}$

Based on the dogma that structure dictates function, ${ }^{10)}$ it follows that differences in physicochemical properties (e.g., activity, specificity) may be the result of subtle variations in protein conformation. ${ }^{11)}$ Hydrophobic effects and electrostatic interactions are two parameters that influence protein structure/ function. Differences in hydrophobicity and charge (zeta potential) between several aspartyl proteinases have been documented ${ }^{6}$; chymosin was reported to have high hydrophobicity and low charge. Yada and Nakai ${ }^{6)}$ hypothesized that alternation of these parameters in other aspartyl members may produce proteinases with properties that more closely resemble those of chymosin (e.g., high MC/PA). This hypothesis has been partially tested in a structure-function study of the aspartyl pro-

$\uparrow$ To whom all correspondence should be addressed. 
teinase from $M$. miehei ${ }^{12)}$; decreased negative charge in this proteinase through chemical modification of carboxyl groups lowered the MC/PA. A similar finding was reported for carboxyl-modified porcine pepsin. ${ }^{13,14)}$

The effects of increased negative charge in aspartyl proteinases have also been examined. Carbamylation of the amino terminus and lysyl residues in MMP reportedly increased the ionic character and decreased the proteolytic activity of the fungal enzyme ${ }^{15)}$; however, the effects of modification on milk-clotting activity were not examined. Increased negative charge through covalent attachment of a polyanionic copolymer to the lysyl residue in porcine pepsin decreased both proteolytic and milk-clotting activities. ${ }^{16)}$

The majority of the studies reporting reduced catalytic activity of chemically modified fungal and mammalian aspartyl proteinases have not found if changes in function were coincident with structural (conformational) changes. In addition, no comparative structure-function study has been done to date on the effects of chemical modification of amino groups in aspartyl proteinases from different (i.e., fungal versus mammalian) sources. Such an investigation may aid in the elucidation of those groups important for catalysis and specificity, and serve to identify differences that account for the observed functional differences within the aspartyl proteinase class of enzymes.

Therefore, this study reports on the structure-function changes in MMP resulting from increased negative charge through chemical modification of amino groups using a watersoluble polyanionic copolymer. Porcine pepsin and chymosin were similarly modified to compare the effects of increased negative charge in mammalian versus fungal aspartyl proteinases.

\section{Materials and Methods}

Materials. MMP was obtained as a lyophilized preparation (Rennet Type II, mutated strain CBS 370.65 , Lot No. 23F-0001) from Sigma Chemical Co., St. Louis, MO. Pepsin (EC 3.4.23.1 from porcine stomach mucosa), rennin (chymosin: EC 3.4.23.4 from calf stomach), 2[N-morpholino] ethanesulfonic acid (MES), and 2,4,6trinitrobenzenesulfonic acid (TNBS) solution were also products of Sigma Chemical Co. Ethylene/maleic anhydride copolymer (EMA) was purchased from Aldrich Chemical Co., Montreal, PQ.

Enzyme purification. MMP was purified using gel permeation chromatography (Sephadex G-25, Pharmacia, Uppsala, Sewden) and horizontal isoelectric focusing. ${ }^{17)}$ Pepsin and chymosin were used without further purification.

Modification of amino groups. Free amino groups in the proteinases were modified using the procedure of Lowenstein $^{16)}$ with modification. Two hundred $\mathrm{mg}$ of protein and $300 \mathrm{mg}$ of EMA were suspended in $10 \mathrm{ml}$ of $0.05 \mathrm{M}$ sodium phosphate buffer ( $\mathrm{pH} 5.8$ ). This quantity of EMA was selected, after testing amounts from 50 to $500 \mathrm{mg}$ (results not shown), to minimize the extent of copolymer crosslinking and subsequent gel formation, while simultaneously obtaining a high degree of protein modification. The reaction between protein and copolymer proceeded for $12 \mathrm{hr}$ at $25^{\circ} \mathrm{C}$; the $\mathrm{pH}$ was maintained at $\mathrm{pH} 5.8$ $+/-0.2$. Following incubation, EMA-aspartyl proteinase and EMA were precipitated with $0.5 \mathrm{M} \mathrm{HCl}$ to a final $\mathrm{pH}$ of 2.2 , and centrifuged for $20 \mathrm{~min}$ at $17,000 \times g\left(4^{\circ} \mathrm{C}\right)$. The recovered precipitate was washed with $5 \mathrm{mI}$ of $0.1 \mathrm{M}$ potassium chloride/ $\mathrm{HCl}$ buffer $(\mathrm{pH} 2.2$ ). Centrifugation and washing were repeated five times. The pellet was resuspended in $5 \mathrm{ml}$ of $0.5 \mathrm{M}$ sodium phosphate buffer and the $\mathrm{pH}$ adjusted to 5.8 ; the final volume was $10 \mathrm{ml}$. Modified proteinases were lyophilized and stored at $-20^{\circ} \mathrm{C}$.

Measurement of the extent of modificantion. The average number of EMA molecules bound per aspartyl proteinase molecule was calculated from the number of residual free amino groups. These were measured by the TNBS $\operatorname{method}^{18)}$ and by amino acid analysis after reductive methylation with formaldehyde and sodium borohydride. ${ }^{19)}$ Analyses were done in triplicate.

Protein concentration. The protein in $1 \mathrm{mg} / \mathrm{mI}$ suspensions of lyophilized native and amino-modified samples was measured using the molar absorption coefficient $1.18 \times 10^{4}$ at $280 \mathrm{~nm}$ for $\mathrm{MMP}^{20)}$, and $5.10 \times 10^{4}$ and $1.43 \times 10^{4}$ at $278 \mathrm{~nm}$ for porcine pepsin ${ }^{21)}$ and chymosin, ${ }^{22)}$ respectively, and confirmed using a modified Lowry method $^{23)}$ with bovine serum albumin as the standard.

Physicochemical characterization. The protocols used for measurement of proteolytic activity (acid-denatured hemoglobin), milk-clotting activity (Berridge substrate), pepstatin A inhibition, thermostability, pH-stability, agarose gel electrophoresis, and amino acid composition of native and amino-modified enzymes were as previously reported. ${ }^{12,17)}$ 
Circular dichroism spectroscopy (CD). CD spectra were measured using a Jasco J-600 spectropolarimeter (Japan Spectroscopic Co., Ltd., Tokyo, Japan) under a constant $\mathrm{N}_{2}$ flush at $25^{\circ} \mathrm{C}$. Enzyme samples were suspended in $20 \mathrm{~mm}$ MES buffer ( $\mathrm{pH} 5.5$ ) to protein concentrations of 0.1 and $0.01 \mathrm{mg} / \mathrm{ml}$ for near-UV and far-UV CD measurements, respectively, filtered through $0.45 \mu \mathrm{m}$ MSI MicronSep cellulosic membrane filters (Fisher Scientific, Toronto, ON) and deaerated before CD analysis. Near-UV (240-320 nm) and far-UV $(190-250 \mathrm{~nm}) \mathrm{CD}$ spectra were obtained within 30 min of sample preparation as described by Yada and Nakai. ") Spectra were corrected for buffer. The proportions of secondary structure fractions ( $\alpha$-helix, $\beta$-sheet, $\beta$-turn, and random) were measured using the Jasco Protein Secondary Structure Estimation Program (Japan Spectroscopic Co.) based on the method of Chang et al. ${ }^{24}$

Statistical analysis. Data were analyzed using ANOVA and Duncan's new multiple range test. ${ }^{25}$ \}

\section{Results}

\section{Assessment of degree of modification}

Amino acid analysis showed that native MMP, porcine pepsin, and chymosin contained 10,1 , and $8 \varepsilon$-amino groups (i.e., lysyl residues) per molecule of protein, respectively. These values were in accordance with those previously reported for MMP, ${ }^{17)}$ porcine pepsin, ${ }^{26)}$ and chymosin. ${ }^{27)}$ Amino acid analysis following reductive methylation of EMA-modified enzymes indicated that $100 \%$ of the lysyl residues were modified (results not shown). Measurement of the residual free primary amino groups in the proteinases using the TNBS method showed that on average only $20 \%$ of these groups were modified (results not shown). These findings suggested that reaction of the different proteinases with EMA under the selected conditions resulted in modification of principally lysyl residues. A similar finding was reported for EMA modification of porcine pepsin. ${ }^{16)}$

\section{Physicochemical characterization}

Agarose gel electrophoresis showed that EMA-modified proteinases had increased net negative charge, i.e., electrophoretic mobility toward the cathode was greater for aminomodified samples compared to native counterparts (Table I). Modified MMP showed the
Table 1. Relative Electrophoretic Mobility

VALUES FOR NATIVE AND AMINO-MODIFIED Mucor miehei Proteinase (MMP), PoRcine Pepsin, And Chymosin

\begin{tabular}{lc}
\hline \multicolumn{1}{c}{ Enzyme sample } & $\begin{array}{c}\text { Relative electrophoretic } \\
\text { mobility value }\end{array}$ \\
\hline Native MMP & 0.70 \\
Amino-modified MMP & 1.00 \\
Native pepsin & 0.75 \\
Amino-modified pepsin & 0.83 \\
Native chymosin & 0.35 \\
Amino-modified chymosin & 0.54 \\
\hline
\end{tabular}

"Values are averages of duplicate measurements.

Table II. Milk-clotting Activity (MC), Proteolytic Activity (PA) and MC/PA of Native and AMINo-Modified Mucor miehei ProteInASE (MMP), Porcine Pepsin, and Chymosin

\begin{tabular}{lccc} 
Enzyme sample & $\begin{array}{c}\mathrm{MC}^{a} \\
(\mathrm{U} / \mathrm{mg})\end{array}$ & $\begin{array}{c}\mathrm{PA}^{b} \\
(\mathrm{U} / \mathrm{mg})\end{array}$ & $\mathrm{MC} / \mathrm{PA}$ \\
\hline Native MMP & $1342(63)^{c}$ & $345(5)$ & 3.9 \\
Amino-modified MMP & $40(3)$ & $57(4)$ & 0.7 \\
Native pepsin & $1153(48)$ & $459(20)$ & 2.5 \\
Amino-modified pepsin & $507(15)$ & $138(6)$ & 3.7 \\
Native chymosin & $1503(52)$ & $274(9)$ & 5.5 \\
Amino-modified & $782(14)$ & $124(6)$ & 6.3 \\
$\quad$ & & & \\
\hline
\end{tabular}

a Measured using Berridge substrate. Values are averages of 10 assays.

$b$ Measured using acid-denatured hemoglobin. Values are averages of 3 assays.

c Values in parentheses are the standard deviations.

greatest cathodic migration and was assigned the relative electrophoretic mobility value of 1.00. All samples, with the exception of native pepsin (see below), resolved into single bands indicating that (i) modified proteinases were essentially free of corresponding native enzyme, and (ii) homogeneous populations of modified proteinases were obtained. Several bands were resolved upon electrophoresis of native pepsin, likely the result of autolysis ${ }^{28}$; the relative electrophoretic mobility value for only the major band is indicated in Table I. Of particular interest was that the autolytic behavior was not demonstrated by aminomodified pepsin. This may be attributed to reduced proteolytic activity of the modified 
enzyme (see below).

Proteolytic and milk-clotting activities of the three aspartyl proteinases were significantly $(p \leq 0.05)$ decreased following amino modification with EMA (Table II). Modified MMP was found to have only 17 and $3 \%$ of native proteolytic and milk-clotting activity, respectively. Reduction of these activities was reflected by decreased MC/PA. Conversely, although both proteolytic and milk-clotting activities of pepsin and chymosin were decreased, proteolytic activity was affected to a greater extent. Consequently, the resulting $\mathrm{MC} / \mathrm{PA}$ for these mammalian proteinases was increased (Table II).

Modification of these enzymes was also reflected by changes in their susceptibility to inhibition by pepstatin A. Incubation of solutions of native proteinases with pepstatin A left less than $1 \%$ residual activity (Table III). Conversely, amino-modified MMP showed the same activity both in the presence and absence of the inhibitor. Both amino-modified pepsin and chymosin remained suceptible to pepstatin A, although the extent of inhibition was reduced (Table III).

The pH-activity optimum of MMP was shifted from $\mathrm{pH} 5.0$ to $\mathrm{pH} 4.5$ as a consequence of modification (Fig. 1A). The $\mathrm{pH}$-activity optimum of pepsin (Fig. 1B) and chymosin (Fig.

Table III. EFFECTS of AMINO MODIFICATION IN Mucor miehei ProteInASE (MMP), PORCINE PePsin, and CHYMOSIN ON THE DEGREE of Inhibition by Pepstatin A

Enzyme sample

$\%$ Residual proteolytic activity $^{a, b}$

\section{Native MMP}

Amino-modified MMP

Native pepsin

Amino-modified pepsin

Native chymosin

Amino-modified chymosin

a Residual proteolytic activity was calculated relative to samples not containing the inhibitor. Samples $(100 \mu \mathrm{g}$ in $0.2 \mathrm{ml} 20 \mathrm{~mm}$ MES buffer (pH 5.5) were incubated with $100 \mu \mathrm{g}$ pepstatin for $30 \mathrm{~min}$ at $25^{\circ} \mathrm{C}$.

$b$ Activity was assayed in triplicate using aciddenatured hemoglobin.
1C) were also altered by modification; however, a shift of $0.5 \mathrm{pH}$ units towards a more alkaline pH optimum was observed for these enzymes.

Proteolytic activity of the native fungal enzyme was unchanged $(p>0.05)$ from 25 to $70^{\circ} \mathrm{C}$, while amino-modified MMP showed maximum activity to only $55^{\circ} \mathrm{C}$. Complete inactivation of both native and modified MMP occurred at about $80^{\circ} \mathrm{C}$ (Fig. 2A). The temperature-activity profile of native porcine pepsin was similar to that previously reported $^{29,30)}$; essentially no activity towards acid-denatured hemoglobin was observed above $70^{\circ} \mathrm{C}$. Modified pepsin showed a similar

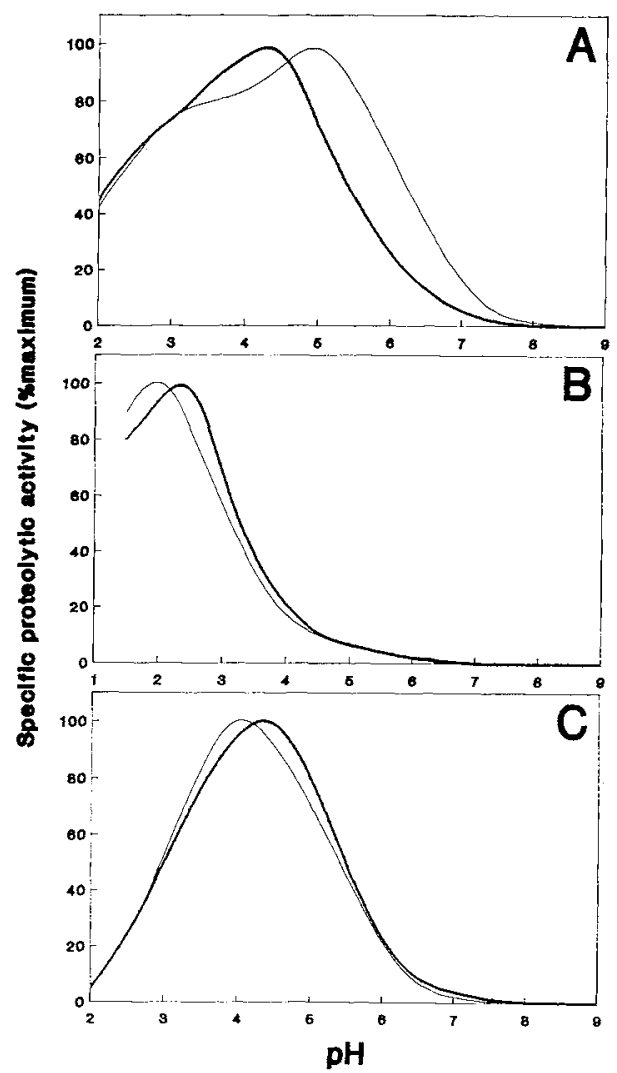

Fig. 1. pH-Activity Profiles of Native $(-)$ and Amino-modified (-) (A) Mucor miehei Proteinase, (B) Porcine Pepsin, and (C) Chymosin.

Enzyme concentration was $1 \mathrm{mg} / \mathrm{ml}$ in $20 \mathrm{~mm}$ buffers ranging in $\mathrm{pH}$ from 2.0 to $9.0(0.5 \mathrm{pH}$ intervals $) .{ }^{17}$ Samples were incubated for 1 hr at $4^{\circ} \mathrm{C}$ subsequent to activity measurement using acid-denatured hemoglobin as substrate. Assays were done in triplicate. 


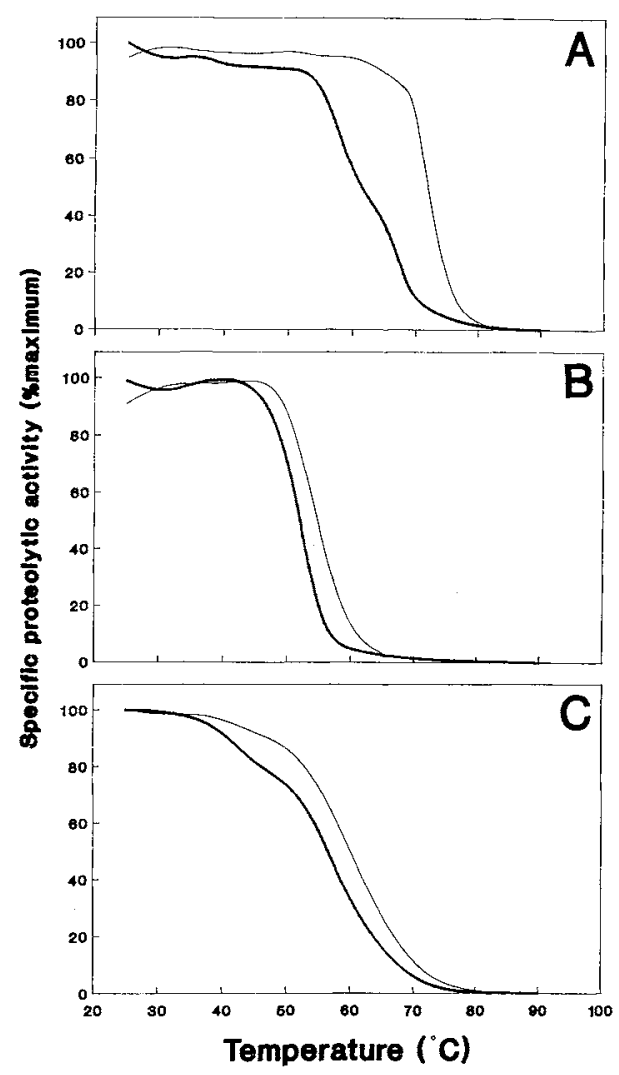

Fig. 2. Thermostability of Native (-) and Aminomodified (-) (A) Mucor miehei Proteinase, (B) Porcine Pepsin, and (C) Chymosin.

Enzyme concentration was $1 \mathrm{mg} / \mathrm{ml}$ in $20 \mathrm{~mm}$ MES buffer (pH 5.5). Samples $(1.0 \mathrm{ml})$ of each proteinase solution were incubated for $10 \mathrm{~min}$ at temperatures from 25 to $90^{\circ} \mathrm{C}\left(5^{\circ} \mathrm{C}\right.$ intervals) and cooled rapidly to room temperature. Proteolytic activity was assayed subsequently using acid-denatured hemoglobin as substrate; measurements were done in triplicate.

response to increased temperature although maximum activity occurred over an abbreviated temperature range (Fig. 2B). Native chymosin was more thermostable than pepsin as indicated by greater $\%$ activity above $60^{\circ} \mathrm{C}$ and continued proteolysis above $70^{\circ} \mathrm{C}$. As with the other proteinases, amino modification of chymosin increased the thermolability of the proteinase (Fig. 2C).

Reduced thermostability of the modified enzymes was further demonstrated by a decrease (relative to native enzyme) in \% residual proteolytic activity following a thermal
Table IV. \% Residual Proteolytic Activity of Native ANd AmINo-modified Mucor miehei Proteinase (MMP), Porcine Pepsin, and Chymosin Following a Thermal Treatment Equivalent to Pasteurization

\begin{tabular}{lcc}
\hline & $\begin{array}{c}\% \text { Residual proteolytic activity } \\
\text { after } 30 \text { min at } 65^{\circ} \mathrm{C}^{*, * *}\end{array}$ \\
\cline { 2 - 3 } & Native & Amino-modified \\
\hline MMP & $96^{a}$ & $45^{b}$ \\
Porcine pepsin & $5^{d}$ & $2^{d}$ \\
Chymosin & $25^{c}$ & $19^{c}$
\end{tabular}

* Relative to activity at $25^{\circ} \mathrm{C}$; measured using acid-denatured hemoglobin.

** Values are averages of triplicate measurements.

$a-d$ Values with the same superscript are not significantly $(p>0.05)$ different.

Table V. Proportions of Secondary Structure FraCtIONS OF NATIVE AND AMINO-MODIFIED Mucor miehei ProteINASE (MMP), PORCINE Pepsin, AND CHYMosin

\begin{tabular}{crrrr} 
& \multicolumn{4}{c}{ Secondary structure fraction $(\%)^{*}$} \\
\cline { 2 - 5 } Sample & $\alpha$-Helix & $\beta$-Sheet & $\beta$-Turn & Random \\
\hline Native MMP & $1.2^{a}$ & $55.7^{h}$ & $15.8^{c}$ & $27.9^{d}$ \\
Amino-modified & $14.3^{c}$ & $28.9^{d}$ & $18.8^{c}$ & $38.0^{f}$ \\
MMP & & & & \\
Native pepsin & $9.4^{b}$ & $41.1^{f}$ & $15.7^{c}$ & $33.8^{e}$ \\
Amino-modified & $10.8^{b}$ & $41.0^{f}$ & $16.6^{c}$ & $31.6^{e}$ \\
pepsin & & & & \\
Native chymosin & $11.7^{b}$ & $47.3^{g}$ & $15.8^{c}$ & $25.2^{d}$ \\
Amino-modified & $10.5^{b}$ & $48.3^{g}$ & $15.6^{c}$ & $25.6^{d}$ \\
chymosin & & & &
\end{tabular}

* Values are averages of triplicate measurements.

$a-n$ Values with the same superscript are not significantly $(p>0.05)$ different.

treatment equivalent to pasteurization (Table IV). Noteworthy was that this reduction was significant $(p \leq 0.05)$ only for MMP.

\section{Structure}

Near-UV CD was used to monitor the effects of amino modification on the tertiary structure of the various proteinases. Figure $3 \mathrm{~A}$ indicates the nearly complete loss of tertiary structure of MMP following modification. The fine structure of the aromatic amino acid residues, apparent in the spectrum of native MMP, was 


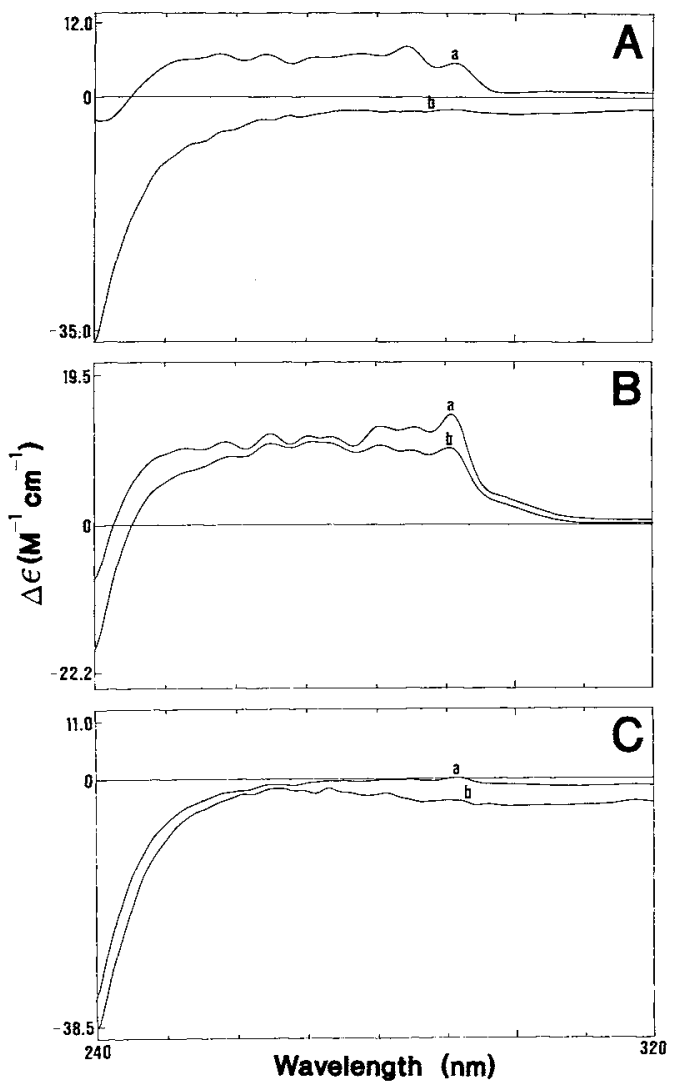

Fig. 3. Near-UV CD Spectra of (a) Native and (b) Amino-modified (A) Mucor miehei Proteinase (B) Porcine Pepsin, and (C) Chymosin.

Enzyme concentration and sample preparation were as described in Materials and Methods.

not detectable in the $C D$ spectrum of the amino-modified enzyme. The tertiary structure of both porcine pepsin and chymosin was relatively unchanged by modification as indicated by the similar spectra for both the native and amino-modified samples (Fig. 3B, C).

A comparable situation was seen for protein secondary structure, indicated by far-UV CD spectra. Table $\mathrm{V}$ shows the proportions of secondary structure fractions and indicates that only MMP was significantly $(p \leq 0.05)$ affected by amino modification.

\section{Discussion}

Ethylene/maleic anhydride copolymer is a polyfunctional crosslinking agent that covalently binds, via its carboxyl groups, to amino groups of proteins. ${ }^{31,32 y}$ In this study, all lysyl residues in the aspartyl proteinases examined were modified using this negatively charged polyelectrolyte. Since generally only lysyl residues participated in the modification reactions, the number of copolymer molecules bound to the proteinases, and the resultant changes in their structure and function, was assumed to be related to the number of available $\varepsilon$-amino groups. Of particular interest, however, was the fact that while both MMP and chymosin contained similar numbers of lysyl residues available for modification (10 and 8 , respectively), only the fungal enzyme showed marked changes in structure and function. Since all lysyl residues were shown to be modified, this finding may be a reflection of the inherent stability differences between the native proteinases, e.g., protein stabilizing hydrophobic effects have been reported to be more predominant in chymosin. ${ }^{6}$ In addition, location of the amino groups in the fungal and calf enzymes may have influenced the degree of modification-induced alteration of structure and function. Modification of amino-bearing residues remote from each other and/or substrate binding/active sites may not have affected protein structure and, therefore, function, to the same extent as modification of amino groups in close proximity. Confirmation of this hypothesis awaits further structural and sequence analyses of these proteinases.

All modified proteinases displayed reduced proteolytic and milk-clotting activities (Table II). Increased net negative charge on the modified enzymes (Table I) may have sufficiently altered the conformation of substrate binding and/or active site(s) thereby altering the specificity of the enzymes towards the macromolecular substrates, i.e., hemoglobin and milk proteins. Alternatively, stearic hinderance due to the bulky EMA group(s) may have physically restricted access of the substrates to the enzyme binding/active site(s). Since both substrates would be negatively charged at the $\mathrm{pH}$ of activity measurement, i.e., 
$\mathrm{pH} \quad 3.5$ and 5.5 for proteolytic activity (hemoglobin) and milk-clotting activity (reconstituted, spray-dried milk proteins), respectively, charge repulsion between substrate and modified enzyme may have also contributed to decreased activity. Considering the different degrees to which each of the proteinases were modified (i.e., the number of lysyl residues available), each of the above mentioned possibilities, either separately or in combination, may account for the observed reductions in enzymatic activity.

Evidence from the pepstatin inhibition study (Table III) together with structural analysis (Fig. 3; Table V) indicated, however, that the conformation of modified pepsin and chymosin was essentially unchanged from that of the corresponding native enzymes (i.e., modified mammalain proteinases remained susceptible to inhibition by pepstatin, and tertiary structure and the proportions of secondary structure fractions were similar to that of native enzymes). Conversely, modified MMP was not inhibited by pepstatin (Table III), and showed substantially altered tertiary structure (Fig. 3) and significant $(p \leq 0.05)$ changes in the proportions of $\alpha$-helix and $\beta$-sheet (Table V). These results suggested that decreased enzymatic activity of the modified mammalian enzymes may be more a product of physical restriction and/or coulombic repulsion of substrate from the enzyme binding/active site, while reduced activity of the modified fungal enzyme may be attributable to modificationinduced alteration of active conformation; the effects of EMA size and charge may have also contributed.

Lowenstein $^{16)}$ reported a shift of $1.5 \mathrm{pH}$ units toward a more alkaline $\mathrm{pH}$ optima following EMA modification of porcine pepsin. A similar trend was obtained in this study; both modified pepsin and chymosin functioned optimally at a $\mathrm{pH} \quad 0.5$ units above native enzyme $\mathrm{pH}$-activity optimum (Fig. 2B, C). Conversely, modified MMP showed maximum catalytic activity at a $\mathrm{pH}$ below that of the native enzyme (Fig. 1A). Increased anionic character of MMP through carbamylation of amino groups has similarly been reported to shift the $\mathrm{pH}$-activity optimum of the enzyme toward acid $\mathrm{pH} .{ }^{15)}$ Shifts in $\mathrm{pH}$-activity optima may be the result of altered intrinsic $\mathrm{pH}$ arising from the polyanion in the vicinity of the active site. ${ }^{16,31,32)}$ The opposite shifts in $\mathrm{pH}$-activity optima observed for the modified fungal and mammalian enzymes may be related to the number and location of lysyl residues proximal to the substrate binding/active site.

Amino-modified MMP was less thermotolerant than the corresponding native enzyme (Fig. 2; Table IV). This suggested that disruption of protein charge density by the polyanion may have decreased the 'conformational stability' of the fungal enzyme; support for this hypothesis is presented in a companion paper. ${ }^{33)}$ This finding is particularly noteworthy since native MMP has the highest thermostability of all the aspartyl proteinases used to clot milk for cheesemaking. ${ }^{9}{ }^{9}$

Results from this study indicated that aspartyl proteinases from different sources that were modified to similar degrees showed dissimilar responses to increased negative charge; MMP appeared to be particularly susceptible to charge destabilization. Further investigation into the importance of charge and other forces (e.g., hydrophobicity) in aspartyl proteinase structure-function is required to better understand the nature of those factors contributing to high MC/PA and substrate specificity, and to aid in the development of systematic modification strategies for the production of more chymosin-like proteinases.

Acknowledgments. The authors thank Dr. A. Clarke for doing the amino acid analyses. This work was supported by the Natural Sciences and Engineering Research Council of Canada.

\section{References}

1) J. Kay, Biochemical Society Transactions, 613th Meeting, 13, 1027 (1985).

2) L. Polgar, "Mechanisms of Protease Action," CRC Press, Inc., Boca Raton, FL, 1989, pp. 157-182.

3) J. Tang and R. N. S. Wong, J. Cell. Biochem., 33, 53 (1987). 
4) B. Foltmann and V. B. Pederson, in "Acid Proteases: Structure, Function and Biology," Advances in Experimental Medicine and Biology, Vol. 95, ed. by J. Tang, Plenum, New York, 1976, pp. 3-22.

5) I.-N. Hsu, L. T. J. Delbaere, M. N. G. James and T. Hofmann, Nature, 266, 140 (1977).

6) R. Y. Yada and S. Nakai, J. Agric. Food Chem., 34, 675 (1986).

7) R. Y. Yada and S. Nakai, J. Food Biochem., 10, 155 (1986).

8) S. Branner-Jorgensen, P. Eigtved and P. Schneider, Neth. Milk Dairy J., 35, 361 (1981).

9) P. Garnot, Int. Dairy Fed. Bull., 194, 2 (1985).

10) G. E. Shulz, C. D. Barry, J. Friedman, P. Y. Chou, G. D. Fasman, A. V. Finkelstein, V. I. Lim, O. B. Ptitsyn, E. A. Kabot, T. T. Wu, M. Levitt, B. Robson and K. Nagano, Nature, 250, 140 (1974).

11) S. Visser, Neth. Milk Dairy J., 35, 65 (1981).

12) J. L. Smith, G. E. Billings, M. F. Marcone and R. Y. Yada, J. Agric. Food Chem. (1991), in press.

13) C.-Y. Ma and S. Nakai, J. Dairy Sci., 63, 705 (1980).

14) C.-Y. Ma and S. Nakai, J. Agric. Food Chem., 28, 834 (1980).

15) W. S. Rickert, Biochim. Biophys. Acta, 271, 93 (1972).

16) H. Lowenstein, Acta Chem. Scand. B, 28, 1098 (1974).

17) J. L. Smith and R. Y. Yada, Can. Inst. Food Sci. Technol. J. (1991), 24 (1/2), 48 (1991).

18) R. Fields, in "Methods in Enzymology," Vol. 25, ed. by C. H. W. Hirs and S. N. Timasheff, Academic Press, New York, 1972, pp. 464468.

19) G. E. Means and R. E. Feeney, Biochemistry, 7, 2192
(1968).

20) M. Ottesen and W. Rickert, Compt. Rend. Trav. Lab. Carlsberg., 37, 301 (1970).

21) P. L. Privalov, P. L. Mateo and N. N. Khechinashvili, J. Mol. Biol., 152, 445 (1981).

22) B. Foltmann, Compt. Rend. Trav. Lab. Carlsberg., 35, 143 (1966).

23) E. F. Hartree, Anal. Biochem., 48, 422 (1972).

24) C. T. Chang, C.-S. C. Wu and J. T. Yang, Anal. Biochem., 91, 13 (1978).

25) SAS Institute Inc., "SAS User's Guide: Statistics, Version 5," SAS Institute Inc., Cary, NC, 1985.

26) A. P. Ryle, in "Methods in Enzymology," Vol. XIX, ed. by G. E. Perlmann and L. Lorand, Academic Press, New York, 1970, pp. 316-336.

27) B. Foltmann, in "Methods in Enzymology," Vol. XIX, ed. by G. E. Perlmann and L. Lorand, Academic Press, New York, 1970, pp. 421-436.

28) F. Ahmad and P. McPhie, Int. J. Peptide Protein Res., 12, 155 (1978).

29) N. F. Haard, L. A. W. Feltham, N. Helbig and E. J. Squires, in "Modification of Proteins: Food, Nutritional, and Pharmacological Aspects," Advances in Chemistry Series 198, ed. by R. E. Feeney and J. R. Whitaker, American Chemical Society, Washington, D.C., 1982, pp. 223-244.

30) E. J. Squires, N. F. Haard and L. A. W. Feltham, Biochem. Cell Biol., 64, 205 (1986).

31) L. Goldstein, Y. Levin and E. Katchalski, Biochemistry, 3, 1913 (1964).

32) Y. Levin, M. Pecht, L. Goldstein and E. Katchalski, Biochemistry, 3, 1905 (1964).

33) J. L. Smith and R. Y. Yada, Agric. Biol. Chem., 55, 2017 (1991). 